\title{
Effect of Low Temperature Plasma Nitriding on Salt Spray Corrosion and Electrochemical Corrosion of H13 Hot Work Mould Steel
}

\author{
Zhao Wen, Kong Dejun* \\ School of Mechanical Engineering, Changzhou University, Changzhou 213164, China \\ *E-mail: kong-dejun@163.com \\ doi: $10.20964 / 2018.09 .53$
}

Received: 5 May 2018 / Accepted: 26 June 2018 / Published: 5 August 2018

\begin{abstract}
A nitrided layer was fabricated on $\mathrm{H} 13$ hot work mould steel using a low temperature plasma nitriding (LTPN). The morphologies, distributions of chemical elements and phases of obtained nitrided layer were characterized using a scanning electron microscopy (SEM), energy dispersive spectrometer (EDS) and X-ray diffractometry (XRD), respectively, its nanohardness and modulus of elasticity was measured using a nanoindentation, and its bonding strength was tested using a scratch test. The corrosion properties of substrate and nitrided layer were analyzed using a salt spray corrosion and electrochemical corrosion. The results show that the nitrided layer is primarily composed of nitrides, whose nanohardness and modulus of elasticity is 11.0 and $213.0 \mathrm{GPa}$, respectively, and the average bonding strength of nitrided layer is $50.23 \mathrm{~N}$ measured by scratch test, showing high bonding strength between the nitrided layer and the substrate. The corrosion products on the substrate and nitrided layer after SSC are $\gamma-\mathrm{FeOOH}$ and $\alpha-\mathrm{FeOOH}$, of which the $\alpha-\mathrm{FeOOH}$ prevents further the nitride layer and substrate from corrosion. The corrosion potential of substrate and nitrided layer is -0.79 and $-0.65 \mathrm{~V}$, respectively, exhibiting that the nitrided layer has higher electrochemical corrosion resistance. The capacitive impedance loop of nitrided layer is significantly larger than that of substrate, its lowest measurement frequency $|Z|_{0.01 \mathrm{~Hz}}$ and low-frequency phase angle values are also greater than the substrate, showing that the nitrided layer is acted as an effective anti-corrosion barrier layer to prevent corrosive ions from entering into the substrate, which increases its electrochemical corrosion resistance.
\end{abstract}

Keywords: low temperature plasma nitriding (LTPN); nitrided layer; salt spray corrosion (SSC); electrochemical corrosion; corrosion mechanism

\section{$\underline{\text { FULL TEXT }}$}


(C) 2018 The Authors. Published by ESG (www.electrochemsci.org). This article is an open access article distributed under the terms and conditions of the Creative Commons Attribution license (http://creativecommons.org/licenses/by/4.0/). 